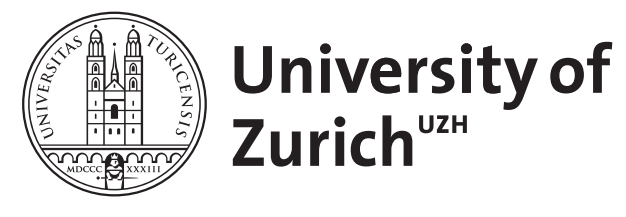

\title{
Multistage density dependence in an amphibian.
}

Altwegg, R

\begin{abstract}
Density dependence is the major process keeping the sizes of natural populations within bounds. In organisms with complex life cycles, the stage at which density dependence occurs and whether it occurs in one or several life stages have important consequences for the dynamics of their populations. I manipulated density of pool frogs ( Rana lessonae) during the aquatic larval and the terrestrial juvenile stages and examined the effect on growth and survival until 1 year of age. High larval density, but not high juvenile density, led to smaller size at this age. Both larval and juvenile density led to reduced growth during the early juvenile stage, but the effect of the larval density appeared stronger than the effect of juvenile density. No density dependence in survival could be found. My results suggest that density dependence in both the larval and the terrestrial juvenile stage may play important roles in the regulation and dynamics of amphibian populations.
\end{abstract}

DOI: https://doi.org/10.1007/s00442-003-1248-x

Posted at the Zurich Open Repository and Archive, University of Zurich

ZORA URL: https://doi.org/10.5167/uzh-504

Journal Article

Published Version

Originally published at:

Altwegg, R (2003). Multistage density dependence in an amphibian. Oecologia, 136(1):46-50.

DOI: https://doi.org/10.1007/s00442-003-1248-x 


\section{Res Altwegg \\ Multistage density dependence in an amphibian}

Received: 5 August 2002 / Accepted: 8 March 2003 / Published online: 17 April 2003

(C) Springer-Verlag 2003

\begin{abstract}
Density dependence is the major process keeping the sizes of natural populations within bounds. In organisms with complex life cycles, the stage at which density dependence occurs and whether it occurs in one or several life stages have important consequences for the dynamics of their populations. I manipulated density of pool frogs (Rana lessonae) during the aquatic larval and the terrestrial juvenile stages and examined the effect on growth and survival until 1 year of age. High larval density, but not high juvenile density, led to smaller size at this age. Both larval and juvenile density led to reduced growth during the early juvenile stage, but the effect of the larval density appeared stronger than the effect of juvenile density. No density dependence in survival could be found. My results suggest that density dependence in both the larval and the terrestrial juvenile stage may play important roles in the regulation and dynamics of amphibian populations.
\end{abstract}

Keywords Complex life cycle - Density manipulation · Population dynamics - Population regulation - Rana lessonae

\section{Introduction}

One of the central debates in population ecology during much of the last century has been whether natural populations are regulated by density-dependent mechanisms or driven by density-independent factors (Nicholson 1933; Andrewartha and Birch 1954; Wolda 1989; Berryman 1991). Recently, this debate has been consid-

\footnotetext{
R. Altwegg (

Institute of Zoology, University of Zürich,

Winterthurerstrasse 190, 8057 Zürich, Switzerland

e-mail: altwegg@uvic.ca

Tel.: +1-250-7217127

Fax: +1-250-7217120

Present address:

R. Altwegg, Department of Biology,

University of Victoria, Victoria, BC, V8 W 3N5, Canada
}

ered to be resolved (Wolda 1995; Turchin 1999). It seems unlikely that populations could persist through time without some form of density dependence (Royama 1977). An interesting task now is to uncover when density dependence occurs in species' life cycles (Hanski 1990).

The action of density dependence can be complicated in organisms with complex life cycles. These organisms have abrupt ontogenetic changes in morphology, termed metamorphosis, which typically are associated with a niche shift (Wilbur 1980). Because the different life stages generally do not overlap in resource use and biotic interactions, populations are structured in such a way that density dependence can act within but not among stages. Whether one or several life stages experience densitydependent regulation, and how density in one stage affects fitness traits in another stage, has important consequences for the dynamics of these populations (Rodriguez 1988; Wilbur 1996; Hellriegel 2000). These effects have been studied in laboratory Drosophila populations, and it became evident that ignoring the multistage action of density dependence can obscure an understanding of the true dynamics of these populations (Prout and McChesney 1985; Rodriguez 1989). Field studies have found density-dependent processes acting on many different fitness correlates throughout the whole life cycle, suggesting that multistage regulation possibly takes place in nature (reviewed by Stubbs 1977; Stiling 1988). It is unknown, however, whether the population dynamics of organisms with complex life cycles are governed by the overriding importance of density-dependent processes at one life stage, or whether several life stages are equally strongly subject to density dependence. Likewise, interactions between density effects in different life stages are largely unexplored. One step towards resolving these questions can be made through field experiments, which independently manipulate density in several life stages under natural conditions. Such studies are almost completely absent from the literature (but, see Pechmann 1994). 
Among organisms with complex life cycles, amphibians provide some of the best-studied examples of densitydependent effects (Brockelman 1969; Semlitsch and Caldwell 1982; Smith 1983; Petranka 1989). Still, published studies have almost exclusively concentrated on effects in the aquatic stage of larval density, while the importance of density-dependent processes during the terrestrial stage remains largely unknown (but, see Pechmann 1994; Golay 1996). Here, I experimentally investigated the effect of density manipulations during the tadpole and terrestrial juvenile stages in the pool frog Rana lessonae Camerano. I examined the consequences of density manipulations for survival until 1 year of age and body size and body mass at 1 year of age (8-9 months past metamorphosis). The results identify periods during the first year of life at which individual performance may be density dependent and therefore address the possibility that population dynamics are determined by multistage regulation.

\section{Materials and methods}

Study organism

This section provides a brief description of the biology and life history of Rana lessonae (see Günther 1990 for a thorough review and references). $R$. lessonae is the smallest member of the Rana esculenta species complex present in Switzerland. It breeds between early May and mid-June, mostly in permanent ponds. The tadpoles metamorphose between early July and early October and cannot survive the winter in the larval stage. During metamorphosis, when they switch from feeding on algae to becoming predators of small invertebrates, individuals do not eat and can lose more than half of their body mass. The terrestrial stage starts with a period of fast growth until maturity is reached in the second summer at the earliest (Altwegg and Reyer 2003). Young and adult frogs can be found in or near ponds between early April and late October. They spend the winter buried in the topsoil layer in forests near the ponds where they breed (Holenweg and Reyer 2000).

\section{Experimental procedures}

I manipulated densities of tadpoles and terrestrial juveniles of $R$. lessonae. Two levels of density in each of these two stages were cross-classified, resulting in four treatments. The experimental units were 1,100-1 fiberglass cattle tanks for the larvae, and 9- $\mathrm{m}^{2}$ field enclosures for the terrestrial juveniles (Pechmann 1995). Both stages grew up outdoors, under conditions that closely matched natural conditions. Low-density units received 25 individuals in both stages, while high-density units held 75 individuals. These densities span a wide range of the naturally observed tadpole densities (J. Van Buskirk, unpublished data) and lie within the range of terrestrial juvenile densities observed along the edge of ponds, where they spend the fall (personal observation). Each treatment combination was replicated three times, arrayed in three spatial blocks. The block structure was maintained in the larval and terrestrial part of the experiment, and all analyses were performed on mean values within field enclosures.

Cattle tanks were filled with tap water on 8 May 2000 and covered with shade cloth to prevent colonization by insects. On 9 May, I added to every tank $400 \mathrm{~g}$ of air-dried deciduous leaf litter and $7.5 \mathrm{~g}$ commercial rabbit chow and inoculated them with phytoplankton and zooplankton obtained from a natural pond. No additional food was provided throughout the experiment. I obtained tadpoles of $R$. lessonae from crosses between seven pairs of adult frogs caught on 16 May 2000 in a pond near Hellberg, Kanton
Zürich, Switzerland. On 2 June, when the tadpoles had reached stage 25 (Gosner 1960), I randomly assigned groups of tadpoles to the experimental units in such a way that every replicate received the same proportion of individuals from all families, and raised them under standard conditions (see Semlitsch 1993 for a more detailed description of the artificial ponds).

When the first individual metamorphosed (stage 42, Gosner 1960) on 13 July, I started searching the tanks for metamorphs at least every second day. I removed metamorphs from the tanks, brought them back to the laboratory, and kept them singly in 1-1 plastic tubs until they completed tail resorption (stage 46). Then I weighed them on an electronic balance (to $\pm 1 \mathrm{mg}$ ), and measured body length, tibia length, and head width using calipers (to $\pm 0.1 \mathrm{~mm})$. I conducted a principal component analysis on the three morphological measures to obtain an overall measure of body size (PC1 explained $98 \%$ of the variance in the original data). Finally, I marked the young frogs individually with toe clips for later identification, and every 3-5 days I released batches of recently metamorphosed individuals into the field enclosures.

The fenced open-top field enclosures were situated in a forest near Kloten, Switzerland, where pool frogs are known to hibernate (Holenweg and Reyer 2000). All 12 enclosures were situated in the same clearing, and enclosures within the same block were adjacent to each other, separated by a single fence. These fences extended ca. $40 \mathrm{~cm}$ into the soil and consisted of fine-meshed steel wiring and robust shade cloth. A $15-\mathrm{cm}$-wide overhanging plastic strip on top of the fence was intended to keep the frogs from climbing across it. Each enclosure had a shallow-bottomed plastic bowl with a diameter of $65 \mathrm{~cm}$ that served as a small permanent pool. I sampled each field enclosure twice between 23 and 28 September 2000 and caught all survivors between 20 April and 30 May 2001 (eight capture occasions). Every encountered froglet was caught, identified, and measured as after metamorphosis. After the fall recaptures, I released them back into their enclosure the same day; during the spring captures of 2001, I removed them from the enclosures and released them at their pond of origin.

I analyzed the effect of larval and terrestrial juvenile density on average mass and size in, and survival until, spring 2001 by MANOVA and subsequent univariate ANOVAs using procedure GLM in SAS (SAS Institute Inc. 1996). I also examined the effect of the density treatments on early terrestrial survival and growth, because this is a time of rapid growth during the first year and appears to be important for winter survival (Altwegg and Reyer 2003). I was interested in whether fast growth in smaller froglets would ultimately eliminate the size differences with larger froglets. Therefore, I chose the absolute difference in mass and size between metamorphosis and September 2000 as a measure of growth. This measure accounted for possible density effects mediated by timing of and size at metamorphosis. I analyzed the treatment effects on mass change, size change and mean survival rates within experimental units by ANOVA. Survival until spring was arcsine transformed prior to analysis in order to meet the assumptions of the ANOVA. No transformation was necessary for the other response variables. Because it was not possible to catch every surviving individual in the fall sample, I used classical capturemark-recapture methods in the program MARK to estimate survival for this time period (Lebreton et al. 1992; White and Burnham 1999). I estimated the survival rate separately for every field enclosure using the Cormack-Jolly-Seber model with time-dependent survival and recapture probabilities. To estimate the survival rates as exactly as possible, I included the effect of body size on the recapture probability in two field enclosures. The estimated recapture probabilities (probability of catching an individual at time $t$ given that it is alive at time $t$ ) ranged from $40 \%$ to $86 \%$ for each of the two occasions, and therefore the froglets caught represent a good sample of all survivors at this time. I accounted for sampling uncertainty by weighting the survival estimates by the inverse of their variance in the ANOVA.

Unfortunately, two of the fences separating enclosures within a block developed leaks, and more than 20 froglets crossed these fences into the neighboring field enclosure. Thus, four experimental units had to be omitted from the analysis. Two of the omitted units 
held the treatment high larval/low juvenile density, one held low larval/high juvenile density, and one held high larval/high juvenile density. The rest of the fences had low leakage rates $(4 \%$, range 0 8 , and $4.3 \%$, range $2.5-8$, emigration from low and high density enclosures). The loss of experimental units precluded the fitting of complicated models. Therefore, I first examined possible differences between blocks. The blocks were similar (all response variables $P>0.35$ ) and therefore omitted from the further analysis.

\section{Results}

\section{Larval stage}

Survival during the larval stage was high and was similar in the two larval densities (low: 96.3\%, $\mathrm{SE}=1.0$; high: $96.0 \%, \mathrm{SE}=1.2 ; \mathrm{LR} \chi^{2}=0.04, P=0.84$, using a GLIM model with binomial errors in procedure GENMOD in SAS, SAS Institute Inc. 1996). Therefore, the larval density treatments were maintained during the course of the experiment. Tadpoles growing under high larval densities metamorphosed at a smaller size and later than tadpoles experiencing low larval density. The tank mean responses between treatments did not overlap: mass at metamorphosis was $948 \mathrm{mg}$ (range: 862-1059) in the low and $389 \mathrm{mg}$ (range: 357-411) in the high density treatment ( $n=15$ and $n=6$, respectively); size at metamorphosis (PC1 score, range) was $0.94(0.67-1.22)$ and -0.89 (-1.05 to $-0.76)$, respectively; length of larval period was 59 days (57-62) and 65 days (63-70), respectively.

Terrestrial juvenile growth and survival

The MANOVA showed that larval density affected fitness components of terrestrial juveniles (Wilks $\lambda=0.003$, $\left.F_{3,2}=250.7, P=0.004\right)$. Neither terrestrial juvenile density nor an interaction between the two density treatments had a significant effect in the multivariate space (both $P>0.15)$.
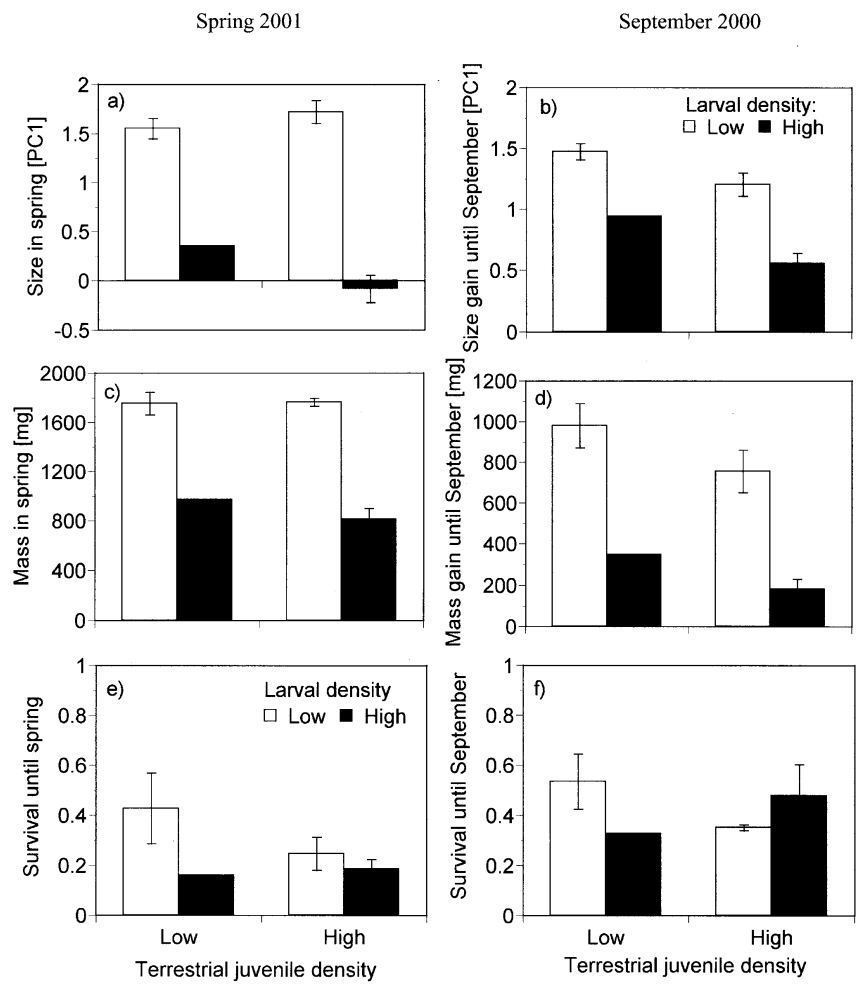

Fig. 1 Average size (a) and mass (c) at, and survival until, spring (e). Average size gain (b) and mass gain (d) between metamorphosis and end of September and survival until end of September (f) of juvenile Rana lessonae subjected to the four possible combinations of low and high larval and juvenile densities. Error bars show the standard deviation. Due to a misfortune, one treatment had only one replicate. Size is the first principal component extracted from measurements of body length, head width, and tibia length (see Materials and Methods)

High larval, but not high terrestrial juvenile, density led to significantly lower mass and smaller size among the survivors at 1 year of age (Table 1a, Fig. 1a, c). Mass and size at this age may be affected by non-random

Table 1 Summary of ANOVA of size and mass at and survival to one year of age (a) and growth and survival from metamorphosis until the end of September (b)

\begin{tabular}{|c|c|c|c|c|c|c|c|c|c|c|}
\hline \multirow[t]{2}{*}{ Source } & \multirow[t]{2}{*}{$d f$} & \multicolumn{3}{|l|}{ Size } & \multicolumn{3}{|l|}{ Mass } & \multicolumn{3}{|l|}{ Survival } \\
\hline & & Type III MS & $\boldsymbol{F}$ & $P$ & Type III MS & $\boldsymbol{F}$ & $P$ & Type III MS & $\boldsymbol{F}$ & $\boldsymbol{P}$ \\
\hline \multicolumn{11}{|l|}{ (a) One year of age } \\
\hline $\begin{array}{l}\text { Larval density (L) } \\
\text { Juvenile density }(\mathrm{J}) \\
\mathrm{L} \times \mathrm{J} \\
\text { Error }\end{array}$ & $\begin{array}{l}1 \\
1 \\
1 \\
4\end{array}$ & $\begin{array}{l}3.550 \\
0.071 \\
0.082 \\
0.015\end{array}$ & $\begin{array}{r}235.2 \\
4.7 \\
5.4\end{array}$ & $\begin{array}{r}<0.001 \\
0.096 \\
0.080\end{array}$ & $\begin{array}{r}1290276 \\
9614 \\
12451 \\
6336\end{array}$ & $\begin{array}{r}203.6 \\
1.5 \\
2.0\end{array}$ & $\begin{array}{r}<0.001 \\
0.286 \\
0.233\end{array}$ & $\begin{array}{l}0.059 \\
0.011 \\
0.022 \\
0.013\end{array}$ & $\begin{array}{l}4.7 \\
0.9 \\
1.7\end{array}$ & $\begin{array}{l}0.096 \\
0.410 \\
0.257\end{array}$ \\
\hline \multirow[t]{2}{*}{ Source } & \multirow[t]{2}{*}{$d f$} & \multicolumn{3}{|l|}{ Growth, size } & \multicolumn{3}{|l|}{ Growth, mass } & \multicolumn{3}{|l|}{ Survival } \\
\hline & & Type III MS & $F$ & $P$ & Type III MS & $\boldsymbol{F}$ & $P$ & Type III MS & $\boldsymbol{F}$ & $P$ \\
\hline \multicolumn{11}{|l|}{ (b) Until September } \\
\hline $\begin{array}{l}\text { Larval density (L) } \\
\text { Juvenile density }(\mathrm{J}) \\
\mathrm{L} \times \mathrm{J} \\
\text { Error }\end{array}$ & $\begin{array}{l}1 \\
1 \\
1 \\
4\end{array}$ & $\begin{array}{l}0.596 \\
0.185 \\
0.006 \\
0.006\end{array}$ & $\begin{array}{r}95.3 \\
29.6 \\
0.9\end{array}$ & $\begin{array}{r}<0.001 \\
0.006 \\
0.394\end{array}$ & $\begin{array}{r}624716 \\
65179 \\
1527 \\
9268\end{array}$ & $\begin{array}{r}67.4 \\
7.0 \\
0.2\end{array}$ & $\begin{array}{l}0.001 \\
0.057 \\
0.706\end{array}$ & $\begin{array}{l}0.029 \\
0.004 \\
0.413 \\
0.097\end{array}$ & $\begin{array}{l}0.3 \\
0.0 \\
4.3\end{array}$ & $\begin{array}{l}0.616 \\
0.847 \\
0.108\end{array}$ \\
\hline
\end{tabular}


mortality with respect to mass or size. To get a better estimate, I examined juvenile growth during the early fall, from metamorphosis until September, when more individuals were still alive.

Juvenile increase in mass and size was reduced by high larval density and high juvenile density (Table 1b, Fig. 1b, d), the effect of juvenile density on mass change being marginally non-significant. On average, the effect of the larval density treatment was three times more powerful in reducing size and mass growth than was the terrestrial juvenile density treatment. Survival during the terrestrial juvenile stage was not significantly affected by either density treatment (Table 1a, b; Fig. 1e, f).

\section{Discussion}

The main contribution of this study was to quantify the impacts of larval and juvenile density on the growth and survival of juveniles in a frog species. I found strong independent density effects of both life stages on juvenile growth in the first year. However, under the densities chosen in this experiment, the effect of larval density was considerably stronger than the effect of terrestrial juvenile density, and only the former led to lower mass and size in spring. Survival was not significantly affected by the density treatments. The strength of the approach chosen here is that the effect of density in the two stages could be measured independently and in a common currency, namely, terrestrial juvenile growth and survival. Several models suggest that population dynamics of amphibians are most sensitive to variation in terrestrial juvenile performance (Taylor and Scott 1997; Som et al. 2000; Biek et al. 2002; Vonesh and De la Cruz 2002).

Earlier studies of amphibians observed strong negative effects of density on larval fitness traits and suggested that populations are regulated at this stage (Brockelman 1969; Semlitsch and Caldwell 1982; Smith 1983; Petranka 1989). Expanding on these results and in agreement with the few available earlier studies (Scott 1994; Morey and Reznick 2001; Altwegg 2002; Altwegg and Reyer 2003), my experiment showed that high larval density also had strong negative effects on the subsequent terrestrial stage. At the chosen densities, the effect of a threefold increase in larval density was considerably stronger than the effect of a similar increase in terrestrial juvenile density. Under more natural settings, two factors may further decrease the importance of density dependence in the terrestrial juvenile stage compared to the larval stage. First, density-dependent predation on the tadpoles would tend to reduce the fluctuations in density of freshly metamorphosed froglets (while simultaneously reducing the density effect on larval growth; Van Buskirk and Yurewicz 1998). Second, these fluctuations may further be reduced by density-dependent dispersal at the juvenile frog stage, whereas tadpoles are confined to discrete ponds. On the other hand, the duration of the aquatic life stage in Rana lessonae is short compared to the terrestrial life stage, potentially increasing the impor- tance of the longer-lasting effect despite its lower intensity.

Models show that density-dependent processes acting in more than one life stage generally lead to more stable population dynamics compared to the case where only one stage is subject to density dependence (Rodriguez 1988; Wilbur 1996; Hellriegel 2000). In light of these models, my results give some preliminary insight into the effects of density on Rana lessonae populations. The experiment showed that growth during the early terrestrial stage was reduced more by high larval density than by high terrestrial juvenile density. This pattern tends to stabilize population dynamics (Wilbur 1996; Hellriegel 2000). On the other hand, the main effect of density was to reduce growth rather than survival. Reduced growth is likely to lead to delayed maturity or increased mortality later in life, which causes a destabilizing, lagged impact of density (Hellriegel 2000). Clearly, more data are needed before these models can be used to predict amphibian population dynamics.

Compared to the large number of field studies using correlative analyses of life-table parameters to examine density dependence within each stage of a complex life cycle (reviewed in Stubbs 1977; Stiling 1988), experimental evidence is still rare. Two studies manipulated density in different life stages independently and examined its effect under natural conditions (Pechmann 1994; Golay 1996). These studies showed that high terrestrial density negatively affected growth and survival in the anurans Gastrophryne carolinensis and Bufo calamita, but not in the salamander Ambystoma talpoideum. These results, together with two observational studies on natural populations of Rana sylvatica (Berven 1990, 1995), and the present study suggest that density dependence affecting multiple life stages may commonly occur in anurans.

Understanding amphibian population dynamics is an urgent goal in the face of the recently observed global amphibian decline (Houlahan et al. 2000; Vonesh and De la Cruz 2002; Biek et al. 2002). Whether the processes governing amphibian populations and populations of other organisms with complex life cycles are similar or not remains to be shown. It seems clear, however, that empirical data on all life stages are needed for an understanding of population dynamics and species interactions when organisms with complex life cycles are involved (McPeek and Peckarsky 1998).

Acknowledgements Thanks to Sonja Angelone, Martina Arioli, Attila Hettyey, and Beni Schmidt for their help with the field work. Brad Anholt, Barbara Hellriegel, Uli Reyer, Beni Schmidt, Josh Van Buskirk, and three anonymous referees gave helpful comments on earlier versions of the manuscript. This work was supported by Swiss NF grant No. 31-40688.94 to H.-U. Reyer and No. 81ZH68483 to R. A. 


\section{References}

Altwegg R (2002) Trait-mediated indirect effects and complex life cycles in two European frogs. Evol Ecol Res 4:519-536

Altwegg R, Reyer H-U (2003) Patterns of natural selection on size at metamorphosis in water frogs. Evolution (in press)

Andrewartha HG, Birch LC (1954) The distribution and abundance of animals. University of Chicago Press, Chicago

Berryman AA (1991) Stabilization or regulation: what it all means! Oecologia 86:140-143

Berven KA (1990) Factors affecting population fluctuations in larval and adult stages of the wood frog (Rana sylvatica). Ecology 71:1599-1608

Berven KA (1995) Population regulation in the wood frog, Rana sylvatica, from three diverse geographic localities. Aust J Ecol 20:385-392

Biek R, Funk WC, Maxell BA, Mills LS (2002) What is missing in amphibian decline research: insights from ecological sensitivity analysis. Conserv Biol 16:728-734

Brockelman WY (1969) An analysis of density effects and predation in Bufo americanus tadpoles. Ecology 50:632-644

Golay N (1996) Die Kreuzkroete (Bufo calamita) Laur. als Pionierart. Dissertation, University of Basel, Switzerland

Gosner N (1960) A simplified table for staging anuran embryos and larvae with notes on identification. Herpetologica 16:183-190

Günther R (1990) Die Wasserfrösche Europas (Anura-Froschlurche). Die Neue Brehm-Bücherei, 600. Wittenberg Lutherstadt, Germany

Hanski I (1990) Density dependence, regulation and variability in animal populations. Philos Trans R Soc Lond B 330:141-150

Hellriegel B (2000) Single- or multistage regulation in complex life cycles: does it make a difference? Oikos 88:239-249

Holenweg A-K, Reyer H-U (2000) Hibernation behavior of Rana lessonae and $R$. esculenta in their natural habitat. Oecologia 123:41-47

Houlahan JE, Findlay CS, Schmidt BR, Meyer AH, Kuzmin SL (2000) Quantitative evidence for global amphibian population declines. Nature 404:752-755

Lebreton JD, Burnham KP, Clobert J, Anderson DR (1992) Modeling survival and testing biological hypotheses using marked animals: a unified approach with case studies. Ecol Monogr 62:67-118

McPeek M, Peckarsky BL (1998) Life histories and the strengths of species interactions: combining mortality, growth, and fecundity effects. Ecology 79:867-879

Morey S, Reznick D (2001) Effects of larval density on postmetamorphic spadefoot toads (Spea hammondii). Ecology 82:510 522

Nicholson AJ (1933) The balance of animal populations. J Anim Ecol 2:132-178

Pechmann JHK (1994) Population regulation in complex life cycles: aquatic and terrestrial density-dependence in pondbreeding amphibians. Dissertation, Duke University, N.C.

Pechmann JHK (1995) Use of large field enclosures to study the terrestrial ecology of pond-breeding amphibians. Herpetologica $51: 434-450$

Petranka JW (1989) Density-dependent growth and survival of larval Ambystoma: evidence from whole-pond manipulations. Ecology 70:1752-1767
Prout T, McChesney F (1985) Competition among immatures affects their adult fertility: population dynamics. Am Nat 126:521-558

Rodriguez DJ (1988) Models with density regulation in more than one life stage. Theor Popul Biol 34:93-117

Rodriguez DJ (1989) A model of population dynamics for the fruit fly Drosophila melanogaster with density dependence in more than one life stage and delayed density effects. J Anim Ecol $58: 349-365$

Royama T (1977) Population persistence and density dependence. Ecol Monogr 47:1-35

SAS Institute Inc. (1996) SAS / STAT Software: changes and enhancements through release 6.11. SAS Institute Inc., Cary, N.C.

Scott DE (1994) The effect of larval density on adult demographic traits in Ambystoma opacum. Ecology 75:1383-1396

Semlitsch RD (1993) Effects of different predators on the survival and development of tadpoles from the hybridogenetic Rana esculenta complex. Oikos 67:40-46

Semlitsch RD, Caldwell JP (1982) Effects of density on growth, metamorphosis, and survivorship in tadpoles of Scaphiopus holbrooki. Ecology 63:905-911

Smith DC (1983) Factors controlling tadpole populations of the chorus frog (Pseudacris triseriata) on Isle Royale, Michigan. Ecology 64:501-510

Som C, Anholt BR, Reyer H-U (2000) The effect of assortative mating on the coexistence of a hybridogenetic waterfrog and its sexual host. Am Nat 156:34-46

Stiling P (1988) Density-dependent processes and key factors in insect populations. J Anim Ecol 57:581-593

Stubbs M (1977) Density dependence in the life cycles of animals and its importance in $K$ - and $r$ - strategies. J Anim Ecol 46:677688

Taylor BE, Scott DE (1997) Effects of larval density dependence on population dynamics of Ambystoma opacum. Herpetologica $53: 132-145$

Turchin P (1999) Population regulation: a synthetic view. Oikos 84:153-159

Van Buskirk J, Yurewicz KL (1998) Effects of predators on prey growth rate: relative contributions of thinning and reduced activity. Oikos 82:20-28

Vonesh JR, De la Cruz O (2002) Complex life cycles and density dependence: assessing the contribution of egg mortality to amphibian declines. Oecologia 133:325-333

White GC, Burnham KP (1999) Program MARK: Survival estimation from populations of marked animals. Bird Study 46:S120-139

Wilbur HM (1980) Complex life cycles. Annu Rev Ecol Syst 11:67-93

Wilbur HM (1996) Multistage life cycles. In: Rhodes OE, Chesser RK, Smith MH (eds) Population dynamics in ecological space and time. University of Chicago Press, Chicago, pp 75-108

Wolda H (1989) The equilibrium concept and density dependence tests. What does it all mean? Oecologia 81:430-432

Wolda H (1995) The demise of the population regulation controversy. Res Popul Ecol 37:91-93 